tibia-four fractures, three consolidated. fibula-two fractures.

second metatarsal bone-one fracture.

Left scapula-one fracture.

" clavicle-one fracture.

", humerus-three fractures, two consolidated.

" ulna-two fractures, one consolidated.

" fifth metatarsal bone-one fracture.

" femur-four consolidated fractures.

" tibia-five fractures, four consolidated.

"fibula-two fractures. found.

A fourth example, related with less attention to detail, is given by Baudelocque. In the year 1803, he observed fortythree fractures in a new born infant in the Maternite (See Dict. des Sc. Méd., tome xvi, p. 64). All the bones of the limbs were broken nearly in the niddle. Mother had had no accident during pregnancy. Delivery had been rapid and easy. No violence had been exercised on the fœetus. On dissection, all the large bones of the limbs were found broken, some in the middle, others in two places; most of the ribs and most of the cranial bones were also broken. Some of the fractures were consolidated, others in process of reunion.

Arnaud (Nouv. Observ. sur la Pratique des Accoucheurs, p. 92, obs. viii) has briefly described a foetus of four or five months, in whom the bones were separate and movable in the middle of the forearms, thighs, and legs, as if they had been intentionally broken; they seemed only joined by the skin. (Dictionnaire des Dictionnaires de Médecine Français et Etrangers. Par une Société de Médecine, sous le direction du Dr. Fabre. Tome 3me, p. 219. Paris : 1840.)

A case, in which the tibia of a new born child was fractured, is recorded from Carus in the Lancet for 1827-8, vol. ii, p. 14; and, with the succeeding case, is quoted by Dr. Richardson in his Fothergillian Essay. The labour took place at the natural period. The mother, who was twenty-five years old, stated that, during the sixth month of pregnancy, she fell on her abdomen, and felt internal movements immediately afterwards, as if the child were in motion. The child was born alive, but was emaciated and feeble. A transverse wound in the right les passed from the one malleolus to the other. At this point, the tibia was fractured completely through and necrosed. The edges of the wound were in a state of sphacelus. The child died on the thirteenth day.

Billard, in his work on Diseases of Infancy, p. 494, narrates, from Devergie, an example of fracture of the clavicle in a babe newly born. The labour took place naturally, and at the proper period. The mother, in the last month of utero-gestation, had fallen with her abdomen heavily against a table. The child was born with a large tumour on the left clavicle. It died on the eighth day after birth. On dissection, it turned out that the clavicle had been fractured, and that the fractured ends had been rejoined by a large callus, the projection of which had caused the tumour.

Dr. Montgomery, in his elaborate and philosophical essay on Spontaneous Amputation of the Fotal Limbs in Utero, refers to a few cases of intrauterine fractures. He relates the case of a woman eight months pregnant, who fell from a window, twentyfive feet, into the stony street, on her face; her hip-joint was dislocated, and her face and hands cut; but the uterus was not ruptured. She was delivered that night of a dead child, which had some of its bones broken, and had sustained several other injuries. She recovered perfectly.

Dr. Montgomery remarks : "Grætzer, after relating cases of intrauterine fractures recorded by several authors, observes that, on reviewing these cases, it appears that in some the cause was purely mechanical, ard had less effect on the mother than on the foetus."

He also describes another case in which fracture of an arm and wound on the head were produced by an accident happening to the mother. Madame K., when thirty-six weeks preg nant for the third time, fell backwards off a ladder, on the 21st of September. She was stunned, and had pains in the loins and lower belly until her accouchement, which took place on the 6th of October, fifteen days after the accident to the mother. The labour was tedious and painful, but terminated without any interference. The child was thin and puny, and had on its head three wounds or sores, two on the frontal, and one over the occipital bone: they were granulated, and suppurating healthily. In addition to these injuries, the forearm was fractured; but all did well under simple management.

With regard to fracture of the fœtal cranial bones, Dr. Mont- gomery observes: "Instances of injury to the cranial bones before birth have been recorded by Osiander, W. J. Schmitt, Schnuhr, D'Outrepont, and Grætzer; and, still more recently, three well marked cases, in which several fractures were found under bloody tumours, were published by Drs. Flugel and Schelling. iWhen these injuries of the fotal head were first observed, they were attributed to violence by Haller, Rosa, and others, the error of which opinion was first perceived by Roederer and Baudelocque; and it is needless to say how impor. tant is the distinction, especially in a medico-legal point of view."

I have thus adduced various illustrations of cases analogous in many respects to the one which occurred under my own care, ard entirely analogous as to the fact of the existence of fracture of bone. These cases are all so many texts for philosophical discourse; but it will be advisable now to take up such points only as are most interesting in a practical sense.

[To be continued.]

SINGULAR CASE OF PLACENTA PRAVIA: IMMENSE ACCUMULATION OF HYDATIDS IN THE UTERUS : ABSENCE OF FETUS:

By R. Wynne Jones, Esq., Beaumaris.

Mrs. B., aged 25, a healthy subject, and mother of two children, the youngest being four years old, consulted me about the middle of May, under the following circumstances. Having menstruated (?) regularly up to this time, after weaning her last baby, she was surprised to find herself pregnant, having, as she alleged, decidedly " quickened", which she knew "from feeling a movement in the womb, a slight enlargement of the abdomen, a swelling of the legs, and a sense of general debility," etc. Having on the previous two occasions suffered nothing from the ailments and inconveniences usually experienced by pregnant women, she was not much astonished to find herself so far gone with child without being sooner aware of it; but she was quite at a loss to account for " being regular as usual every month". As there was a tendency to constipation of the bowels, I prescribed an aperient to be taken occasionally, and told her that a little time would prove whether she was really pregnant or not.

On the 1st of June, she was attacked with considerable " flooding", which was suppressed by rest and ordinary treatment. The hæmorrhage, however, appears never entirely to have ceased ; for she says she continued more or less " unwell" from that time till July 17th. I was then summoned to her in haste, she having had labour pains some hours, and being represented as "flooding to death". On my arrival, I found the account not much exaggerated. Her cheeks were blanched; her pulse was small and feeble; and very alarming hæmorrhage had taken place, and was still going on. I immediately made an examination, and found, as I had previously suspected, that it was a case of placenta prævia; and I lost not a moment in taking the necessary steps. Fortunately, the os uteri was considerably dilated, and the placenta was so lacerable that $I$ had no difficulty in passing my hand through its substance into the cavity of the uterus, which was fully as large as usual at the seventh or eighth month of pregnancy; but, to my astonishment, I could find no fœtus nor vestige of one. The womb was distended with hydatids, some of which were forced along my arm through the vagina. Having seen these, and being agreeably surprised to find that the discharge was not blood or coagula, I proceeded to detach the placenta, which was attached to the whole circumference of the os uteri. This I succeeded in doing piecemeal, for it was so easily torn that I could not do otherwise; and, on withdrawing my hand, the placenta, and about two-thirds of an ordinary sized chamberpotful of hydatids were expelled through the vagina. There was no further hæmorrhage, though there appeared little uterine contraction. I administered a drachm of ethereal tincture of ergot, and bound the abdomen, as I am in the habit of doing after natural confinements. In about two hours, my friend Dr. Llewelyn Jones came to see my patient, and examined the expelled matters. We found them to consist-lst, of an infinity of transparent hydatids, varying from the size of a marble to that of the smallest pea, united together by a white fibrous or membranous substance; 2 nd, the torn pla centa, which was apparently about the usual size and thickness, but its substance thickly studded with small hydatids, similar to those contained in the uterus. There was no funis. 
My patient soon rallied, and felt very comfortable, occasion. ally discharging small quantities of hydatids, but without any pain. In a few hours, she slept well, passed urine freely, and passed an excellent night. She stated that her breasts had been "tender and lumpy" till about a week ago, when they began to diminish in size, becoming soft and flaccid, and without any secretion of milk. During the two following days, hydatids continued to be discharged, after which the lochia assumed their usual course, and her recovery was as rapid and favourable as under an ordinary accouchement attended with hæmorrhage. At the expiration of a month, she was quite well, and following hei usual avocations and habits.

It is perhaps to be regretted that neither the weight nor measure of the ejected matters could be ascertained; but, in private practice, such accurate details are rarely obtainable: the quantity, however, may be easily surmised, from the size which the uterus had attained.

Remarks. The foregoing case may perhaps not be a solitary one, but I have not been able to discover any record of a like one, and it consequently appears to me worthy of publication. I apprehend-

1. That impregnation took place, but at what period must be uncertain; for menstruation (?) continued regular till within the preceding ten weeks.

2 . That the ovum, from some cause or other, became "blighted"

3. That the placenta, being situated so as to occlude the os uteri, became subject to that condition favourable to the development of hydatids, which could not be expelled until the uterus became so distended as to bring on its contractions, as at the full period of natural gestation.

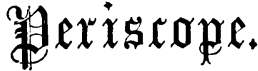

\section{S URGERY.}

\section{FROTTEMENT IN INFLAMMATION OF THE SHEATHS OF TENDONS.}

Dr. Henry Thourson, Surgeon to the Tyrone Infirmary, has a note on this. subject in the Dublin Hospital Gazette for June 15 th, 1857 .

Three cases occurred to him lately, in which the patients complained of pain in different parts of the forearm, the cause of which, without the physical signs above mentioned, would have been obscure. In each instance the patient had been engaged in some work to which he had been previously unac customed. One gentleman was so anxious to get his potatoes set, that he took the spade in his own hand, and laboured with it the greater part of a day. Next morning his arm was useless, from a severe pain along the radial side of the forearm increased to torture whenever he moved his thumb, on which occasions he was sensible of a creaking sound in his arm, so remarkable, that it was mistaken for the crepitus of a fractured bone by the gentleman to whom he first applied; and when Dr. Thompson saw the limb it was done up in splints and bandages secundum artem. He placed a stethoscope on the part, and made the patient apply his ear to it, when he at once compared the noise to the creaking of a new shoe.

A young lady, very fond of the piano and harp, became suddenly, and to herself unaccountably, incapacitated from practising, from a pain along the front of the forearm, in the course of the flexor tendons, greatly increased by stretching the fingers. By catechising her pretty closely, Dr. Thompson found she had been busily engaged in preparing a house for a newly married relative, and had been employing herself in sewing carpets, which were new and heavy, and required a great deal of force to pull the breadths into their places. This was quite enough. On applying his fingers and moving hers, he felt the grating, and at once diagnosed the case.

The other was in an hospital patient, and was very similar to that first described. There was some slight fulness in the affected parts, as well as some tenderness on pressure; but neither was very remarkable, the great complaint being the pain on motion. The cure was somewhat tedious in all, and seemed to be favoured by rest, a few leeches, and cold washes at first, and subsequently by tincture of iodine and liniments ; but ultimately both pain and frottement disappeared.

\section{INTERNAL REMEDIES IN STRANGULATED HERNIA.}

CASE I. Strangulated Hernia returned, under the Influence of Acetate of Lead Enemata. Dr. FLöGEL relates the following case :-Mr. N., whilst dancing, felt an inguinal hernia on the right side (from which he had suffered for some time) becoming strangulated. Taxis, ice, and leeches, did no good; vomiting set in ; and, twenty-seven hours after the strangulation, there was much prostration and hiccough; pulse 140, small and intermitting; skin cold. The hernial tumour was of the size of a goose's egg, hard, immovable, of a dark red, and slightly painful on pressure. An enema was then given, composed of grs. xxij of sugar of lead, in half a pound of water; some ice was, besides, put upon the tumour. An hour afterwards, vomiting and hiccough were less frequent; the enema was repeated. The tumour then became less hard, and the sickness and hiccough ceased; pulse 128. The patient then slept for half an hour, and the swelling diminished one-half, became soft, and was easily reduced. Alvine evacuations were then obtained by purgatives, and the patient left the hospital in perfect health. Dr. Flögel ascribes the successful result to the styptic action of the saturnine salt, which, by causing retraction of the intestine, both in the longitudinal and transverse directions, draws the herniated portion of the bowel into the abdomen. Dr. Flögel adds, that he failed in one case only, viz., that of an old inguinal hernia, where numerous adhesions had formed. The dose of the acetate of lead is from fifteen grains to half a drachm for each enema. The enemata have been administered every hour, without any unpleasant effects. (Ester. Zeitschr. für prakt. Heilkunde; and Lancet.)

CASE II Strangulated Hernia reduced under the influence of the Internal use of Extract of Belladonna. M. Burgatti relates the case of a man, aged 42 , who, whilst busy removing heavy $\operatorname{logs}$ of wood, felt a sudden violent pain in the right groin, a tumour in the same region appearing at the same time. He was obliged to keep his bed; soothing applications were used during the night. Dr. Burgatti found in the morning an inguinal hernia, the tumour of the size of a hen's egg, hard, and not as yet descended into the scrotum. The symptoms of strangulation were very severe. Taxis was immediately tried but the patient could not bear it. M. Burgatti then gave two grains of extract of belladonna every four hours, day and night, and ordered enemata of sweet oil, in which dried camomile had been digested. No change next day was observed in the patient's condition; food and liquids were alike rejected, bust the tumour was less hard. The same treatment was followed. Much improvement was observed on the following day; the vomiting had stopped, and an alvine evacuation had taken place; the face was less anxious; and the patient felt better. Reduction was then extremely easy; and in the course of three days the patient completely recovered. (Il Raccoglit. medico di Fano; and Lancet.)

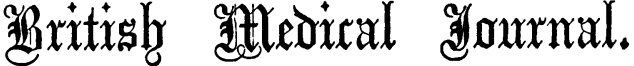

\section{SATURDAY, SEPTEMBER 26TH, 1857.}

\section{S U B U R B A N F I L T H.}

A WrITer in the Times, under the signature of M.R.C.S., calls attention to the necessity for a more stringent supervision of all houses erected for the poor. As he very justly observes, the authorities have taken precaution that fresh air shall be supplied to emigrants on board ship, where it is sometimes difficult to provide it; yet on land, where nothing is easier, the parsimony and the fraud of builders but too often show themselves in running up cottages in which every condition of health is neglected, and successive crops of fevers and other epidemics are ensured for unborn generations. A very capital sketch appeared in Household Words, the other day, of the deplorable condition of that debatable ground between the metro. polis and the country, known as the suburbs of London. Here, 